\title{
Auxiliares de conversación: una oportunidad para desarrollar la competencia intercultural en el aula
}

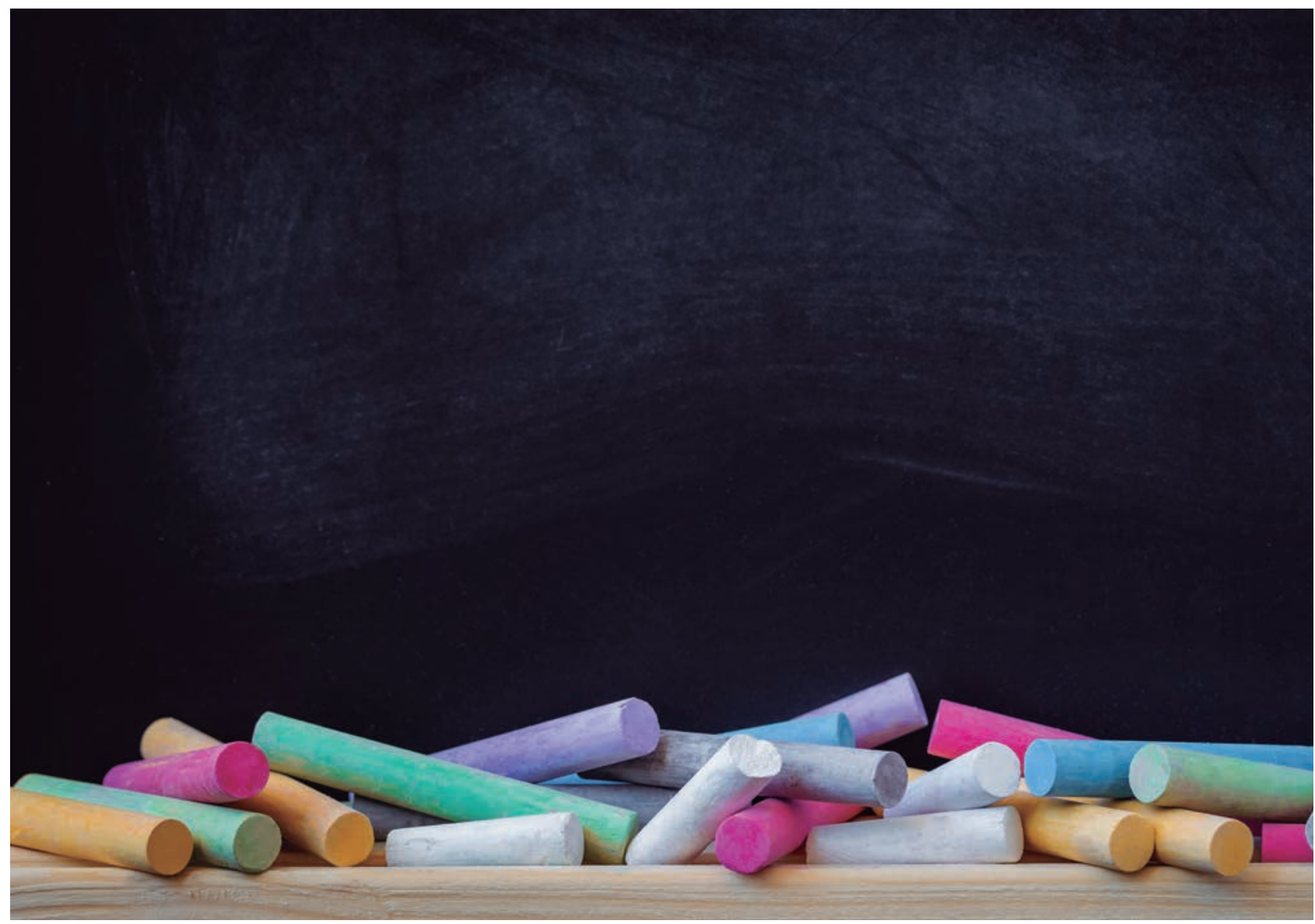

El auxiliar de conversación puede ser una ayuda imprescindible a la hora de desarrollar las destrezas orales en la lengua extranjera. Pero también ofrece la posibilidad a nuestros alumnos de convertirse en ciudadanos globales. La experiencia de conversar y

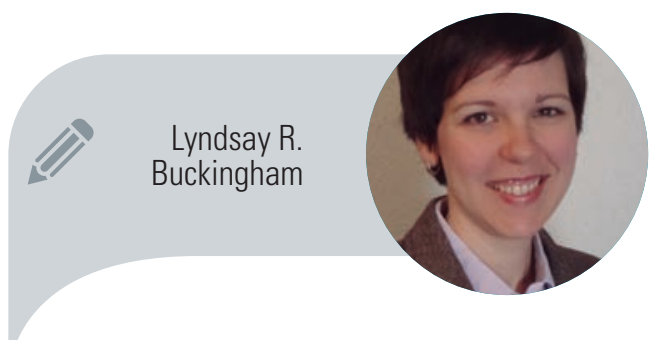

Universidad Pontificia Comillas Irbuckingham@comillas.edu

(y) @rbuckingham colaborar con el auxiliar les ayuda a desarrollar la competencia intercultural, una competencia imprescindible hoy en día. 


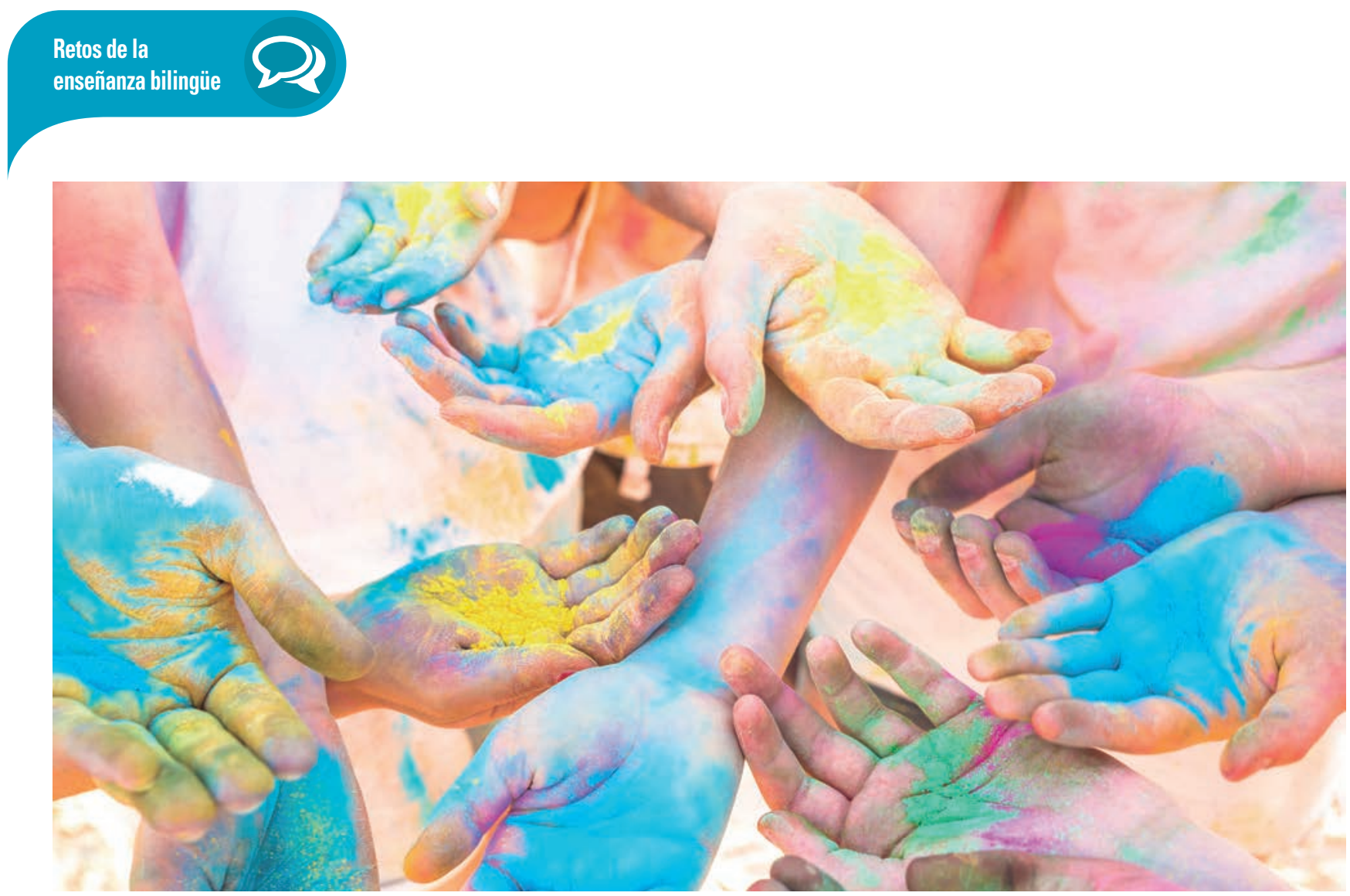

¿Cómo se adquiere la habilidad de trabajar bien con otros? ¿Las de viajar y conversar con gente de otros países? ¿Cómo adquirimos las destrezas que hacen falta para poder entendernos y colaborar con gente extranjera? Muchos pensamos que esto viene con la experiencia vital. Pero, ¿no sería fantástico tener esta experiencia desde la infancia? Muchos de nuestros hijos y alumnos ya tienen la oportunidad de preguntar, conversar y colaborar con gente extranjera en el colegio, por la presencia de los auxiliares de conversación. Vienen de varios países (de habla inglesa principalmente, pero también de habla francesa y alemana) y están allí para ayudarles a aprender el idioma. Pero pueden hacer mucho más; pueden también ayudarles a convertirse en ciudadanos globales.

Hay dos grandes objetivos para la educación plurilingüe: la competencia lingüística y la competencia intercultural (Consejo Europeo, 2003). Entienden esta última como una combinación de conocimiento, destrezas, actitudes y comportamientos que permiten a una persona a reconocer, entender, interpretar y aceptar otras maneras de vivir y pensar ajenas a las propias. Esta competencia es independiente de las habilidades lingüísticas y tan importante como ellas. Desarrollar la competencia intercultural nos enseña a mediar entre nuestra cultura y la de otros para alcanzar un mayor entendimiento, a identificar y hacer uso de estrategias para establecer contacto entre personas, sobrepasando los estereotipos que inhiben una colaboración eficaz.

La competencia intercultural se traslada a nuestro currículo en forma de objetivos de cada etapa educativa. Por ejemplo, se incluye en la Educación Primaria el de "conocer, comprender y respetar las diferentes culturas y las diferencias entre las personas". En la asignatura de Primera Lengua Extranjera, se subraya la importancia de preparar a nuestros pequeños para desenvolverse dentro de esta "sociedad cada vez más interdependiente y global". El aprendizaje de los idiomas extranjeros lógicamente cobra importancia dentro de este marco de objetivos, pero es igualmente importante adquirir una "adecuada sensibilización ante la diversidad de nuestra sociedad, en la aceptación de las diferencias existentes como factor enriquecedor, y en el desarrollo de la comprensión, la tolerancia y la valoración de otras identidades culturales".

Pero, ¿cómo podemos lograr esto? No por aprender un segundo idioma alguien se convierte en una persona más sensible, comprensible y tolerante. Según Michael Byram (1997), la competencia comunicativa intercultural consiste en cinco savoirs, o saberes: 1) savoirs, conocimiento de sí mismo, de otros y de la interacción dentro 
de la sociedad; 2) savoir être, curiosidad y disposición para mirar más allá de sus propias creencias; 3) savoir comprendre, la habilidad de entender e interpretar un hallazgo de otra cultura y poder explicarlo y relacionarlo con su propia cultura; 4) savoir apprendre/faire, la capacidad de adquirir nuevos conocimientos sobre una cultura y sus prácticas y de utilizar su conocimiento, destrezas y actitudes de forma espontánea; 5) savoirs' engager, la habilidad de evaluar y criticar las perspectivas, prácticas y productos de su propia cultura y de otras. Este último savoir engloba a los demás, ya que demanda más de la persona cognitivamente y solo se puede lograr una vez que se dominan los otros. Así, vemos que se trata de una competencia compleja pero a la vez valiosa en una sociedad global como la nuestra.

Entonces, ¿cómo podemos desarrollar esta competencia con nuestros alumnos? A continuación propongo una serie de actividades para aprovechar la presencia del auxiliar de conversación para este fin. Las actividades corresponden a los savoirs para poder trabajar cada aspecto de la competencia comunicativa intercultural.

\section{Conocimiento cultural}

Al principio del curso es interesante que el auxiliar presente información sobre sí mismo y que la vaya ampliando a lo largo del año en forma de presentaciones culturales breves. Sirven para motivar a los alumnos a interactuar con él y les anima a hacerle preguntas para saber más. Las presentaciones pueden centrarse en varios temas: un día típico para él en su país natal; el transporte utilizado en su zona; sus horarios para comidas, trabajo y descanso; su familia, los miembros y su procedencia; su colegio y las características como las asignaturas, espacios, festivales; sus amigos; su pueblo o ciudad natal, las características y situación dentro del país. Hay un sinfín de posibilidades en cuanto al tema. El profesor debería pedir al auxiliar que las presentaciones sean lo más visuales posible y tendrá que explicar bien el nivel lingüístico de los alumnos para que el auxiliar les haga una presen-
Cómo los padres pueden fomentar el desarrollo de la competencia intercultural en sus hijos

Viajar es una manera clara de exponer a nuestros hijos a culturas distintas, pero nuestros recursos y tiempo limitados no siempre lo permiten. Sin embargo, desde casa hay mucho que podemos hacer para ayudarles, como puede ser:

\ Colgar un mapamundi y referirnos a ello siempre que conozcamos a una persona extranjera.

ע Aprender a decir "hola", "gracias" y "adiós" en otros idiomas.

У Leer cuentos, ver películas y escuchar música de orígenes variados.

\ Probar algunos juegos y deportes que provienen de otros países.

$\searrow$ Reflexionar sobre nuestras propias tradiciones y costumbres.

\ Ser positivos en nuestros comentarios hacia personas de orígenes y habilidades distintos.

$\searrow$ Evitar comentarios que promueven estereotipos sobre otras culturas.

๖ Expresar curiosidad por las costumbres de otras culturas y buscar las respuestas en internet.

$\checkmark$ Ayudarles a distinguir entre fuentes factuales y las basadas en opinión en internet.

$\checkmark$ Preguntar a las personas extranjeras que conozcamos por sus experiencias, siempre desde el respeto.

tación acorde a ese nivel. Es importante que el profesor sea explícito en sus indicaciones al respecto, ya que muchos auxiliares no tienen formación ni experiencia docente y necesitan ser guiados.

\section{Curiosidad por el otro}

Una actividad típica para practicar la estructura de la pregunta es hot seat. Consiste en una persona que se sienta delante de los alumnos mientras ellos les hacen preguntas personales. Muchas veces se hace fingiendo ser una persona histórica o famosa, pero para esta propuesta se trata de realizar la actividad con el auxiliar. Los alumnos deben plantearle preguntas sobre su experiencia en su país natal, basándose en las presentaciones culturales, sus conversaciones con él, y lo que hayan estudiado en clase. Además deben preguntarle sobre su llegada a España, cómo se ha sentido al llegar aquí, y qué ve como curioso o distinto de lo que se hace en su país. De este modo, los alumnos aprenden a ver su propia cultura a través de los ojos del otro, y trabajan la empatía. Con esta actividad se pretende que los alumnos desarrollen una curiosi- 


\section{IIII. AQRORA DE PROFESORES}

¿Aprovechas al máximo contar con un auxiliar de conversación? Contesta estas preguntas para averiguarlo.

$\searrow \quad$ ¿Conozco los hobbies y gustos personales de mi auxiliar?

У ¿Sé lo que ha estudiado y a qué le gustaría dedicarse?

$\checkmark \quad$ ¿Le doy tiempo al principio del curso para observar la clase?

$\checkmark \quad$ ¿Planifico un rol específico para el auxiliar los días que esté conmigo?

$\forall \quad$ ¿Le animo a aportar ideas y recursos para mi clase?

У ¿Le comunico la programación de clase con suficiente tiempo para que pueda aportar ideas?

$\checkmark \quad$ ¿Le pongo en contacto con otros auxiliares para que puedan compartir ideas y recursos?

$y \quad$ ¿Tengo una forma de guardar los recursos y actividades que crea el auxiliar para utilizarlos en el futuro?

ע ¿Dedico tiempo a dar feedback constructivo a mi auxiliar sobre su participación en mi aula?

$\forall$ ¿Hablo con mis compañeros para saber lo que hace el auxiliar en sus aulas?

$\searrow \quad$ ¿Animo al auxiliar a conversar con los alumnos mientras estos están trabajando en sus mesas 0 jugando en el patio?

$\searrow \quad$ ¿Le pido que me corrija la expresión oral cuando haga falta?

dad por conocer a gente y costumbres de las culturas ajenas, por aprender más.

\section{Uso de materiales auténticos}

Cuando se hace el primer contacto en verano, la persona responsable de ese contacto con el auxiliar puede pedirle que traiga materiales cotidianos que se pueden luego utilizar en la clase. También muchas veces se pueden descargar de internet una vez que llega el auxiliar a España. Ejemplos de materiales interesantes serían anuncios publicitarios (impresos o vídeos), mapas de sitios públicos (un parque de atracciones, su ciudad, un parque estatal), folletos turísticos de su ciudad y de atracciones turísticas de su zona, entradas (al cine, un museo, un festival local), billetes (de tren o avión), recuerdos de un evento deportivo, periódicos, revistas y cartas de restaurantes. Estos objetos se pueden utilizar como la base de una actividad comunicativa en la que se replica la comunicación auténtica dentro del aula. También pueden servir como un ejemplo de un producto que pueden crear los alumnos en el aprendizaje basado en tareas o proyectos. La idea es que los alumnos se acostumbren a ver y a manejar objetos de otra cultura, que aprendan a interpretar materiales que explican otras costumbres. Por ejemplo, pueden identificar símbolos que son internacionales (como los de los aseos) y otros que sean locales para comparar y contrastar prácticas con las de su país.

\section{Investigación}

Los alumnos pueden escoger algún tema que les ha llamado la atención durante la actividad de hot seat e investigar más con la ayuda del auxiliar. Seguramente, el auxiliar les puede dar pistas a la hora de buscar fuentes fiables y contrastar su opinión y experiencia con las que se encuentran. Podrían, por ejemplo, investigar más sobre un festival local, las razones detrás de alguna costumbre que les resulte curiosa, o un monumento y su origen histórico. Incluso podrían realizar una investigación empírica mediante una encuesta breve y sencilla que el auxiliar puede enviar a sus familiares y amigos, quizá para averiguar sus opiniones sobre un acontecimiento actual. Lo interesante es que investiguen algún tema que les llame la atención para que sientan curiosidad y estén motivados a encontrar las respuestas. Con el resultado de la investigación, pueden realizar un mural para colgar en el aula o en el pasillo, escribir una entrada para el blog de clase, o crear un boletín para enviar a sus padres o a otra clase. Al compartir la información con una audiencia española practican la mediación intercultural.

\section{España para extranjeros}

Algo difícil de conseguir es explicar prácticas culturales propias en un segundo idioma, pero es un paso esencial para poder ganar una perspectiva distinta para poder realizar la evaluación crítica de su propia cultura y de otras. Por esto, los alumnos pueden intentar explicar al auxiliar los fenómenos de la cultura española como son las fiestas de los pueblos, la Semana Santa, el carnaval, los puentes durante el año y las vacaciones de verano, los santos patrones de la localidad y la comida típica de la zona. Muchas veces los auxiliares no llevan mucho tiempo en España y tienen curiosidad por aprender so- 


\section{Tenemos que aprovechar la presencia del auxiliar para crear oportunidades de comunicación auténtica e intercambios culturales que resultarán muy significativos para nuestros alumnos}

bre la cultura española. Les da la excusa perfecta a nuestros alumnos para investigar, si hace falta, estas tradiciones para poder explicárselas. Además, al describir conceptos como un "puente" (refiriéndose a un fin de semana largo) o todo lo que rodea una procesión de Semana Santa, practicarán la estrategia de circunlocución, es decir, explicar un concepto que no tiene traducción a otro idioma. Es una de varias estrategias de comunicación cuyo desarrollo es importante para poder mantener una comunicación fluida.

Siempre que se pueda, se debe ofrecer a los auxiliares la posibilidad de participar en las actividades del centro escolar, para que ellos puedan aportar una visión distinta a lo que se hace. Quizá puedan añadir otra dimensión mediante actividades, canciones o tradiciones propias para hacer el evento más intercultural. Y su mera presencia puede animar a los alumnos a pensar en el evento desde otra perspectiva, más si les pedimos que se lo expliquen o que incluyan al auxiliar de alguna manera. Es más: los auxiliares se sentirán

\section{HEMOS HABLADO DE}

\section{Comunicación intercultural; profesor auxiliar; inglés (segunda lengua); cultura; educación bilingüe.}

Este artículo fue solicitado por PADRES Y MAESTROS en diciembre de 2018, revisado y aceptado en marzo de 2019. valorados y arropados por la comunidad escolar, lo cual estrecha la relación para poder trabajar mejor juntos.

En definitiva, la presencia del auxiliar de conversación en el aula, y en el colegio, nos ofrece una situación de obligación de comunicarse en inglés, lo cual solo existe de forma más artificial entre un profesor español y alumnos españoles. Por eso, tenemos que aprovechar su presencia para crear oportunidades de comunicación auténtica e intercambios culturales que resultarán muy significativos para nuestros alumnos. Poco a poco, a través de muchos momentos de negociación para llegar al sentido de palabras e ideas, los alumnos irán desarrollando la competencia comunicativa intercultural que les servirá a la hora de viajar o hablar con cualquier extranjero que encuentren en su vida diaria
Busca otra manera de realizar un intercambio cultural con otra aula del mundo:

- eTwinning (iniciativa europea para conectar aulas) Connecting Classrooms (British Council)

\section{(D.) DARA SABER MẤS}

BuckingHAM, L. R. (2018). Defining the role of language assistants in the bilingual classroom. Revista Tecnología, Ciencia y Educación (9), 38-49.

Byram, M., Gribkova, B., \& Starkey, H. (2002). Developing the intercultural dimension in language teaching. A practical introduction for teachers. Strasbourg: Council of Europe.

\section{Referencias}

BYRAM, M. (1997). Teaching and assessing intercultural communicative competence. Clevedon: Multilingual Matters.

Consejo Europeo. (2003). Guide for the Development of Language Education Policies in Europe. From Linguistic Diversity to Plurilingual Education. Executive Version. Strasbourg: Council of Europe. Language Policy Division. 